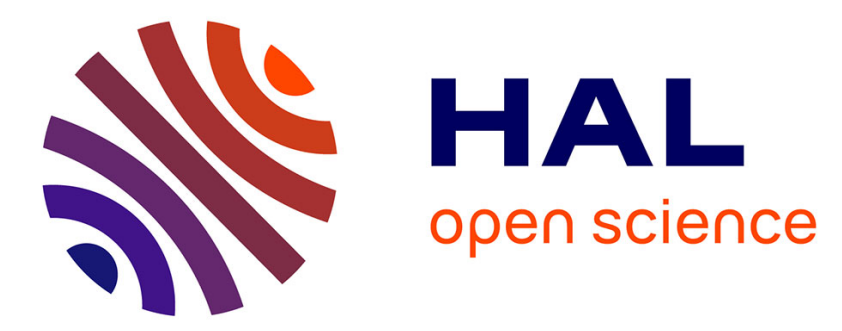

\title{
Evaluation of Currents Induced in Human Body by Plane Wave Exposure At 1-90 MHz
}

Jeanne Frere, Alain Alcaras, Maxim Zhadobov, Christophe Lemoine, Gwenaël Le Cadre, Ronan Sauleau

\section{- To cite this version:}

Jeanne Frere, Alain Alcaras, Maxim Zhadobov, Christophe Lemoine, Gwenaël Le Cadre, et al.. Evaluation of Currents Induced in Human Body by Plane Wave Exposure At 1-90 MHz. EuCAP 2017, Mar 2017, Paris, France. hal-01494934

\section{HAL Id: hal-01494934 \\ https://hal.science/hal-01494934}

Submitted on 24 Mar 2017

HAL is a multi-disciplinary open access archive for the deposit and dissemination of scientific research documents, whether they are published or not. The documents may come from teaching and research institutions in France or abroad, or from public or private research centers.
L'archive ouverte pluridisciplinaire HAL, est destinée au dépôt et à la diffusion de documents scientifiques de niveau recherche, publiés ou non, émanant des établissements d'enseignement et de recherche français ou étrangers, des laboratoires publics ou privés. 


\title{
Evaluation of Currents Induced in Human Body by Plane Wave Exposure At 1-90 MHz
}

\author{
Jeanne Frere ${ }^{1,2}$, Alain Alcaras ${ }^{1}$, Maxim Zhadobov ${ }^{2}$, Christophe Lemoine ${ }^{2}$, Gwenaël Le Cadre ${ }^{1}$, Ronan Sauleau ${ }^{2}$ \\ ${ }^{1}$ Thales Communications \& Security, 110 avenue du Maréchal Leclerc, BP 70945, 49309 Cholet Cedex \\ 2 IETR, UMR CNRS 6164, Université de Rennes 1, 263 avenue du Général Leclerc, 35042 Rennes \\ jeanne.frere@univ-rennes1.fr
}

\begin{abstract}
In existing exposure standards and guidelines the relationship between dosimetric quantities at a given frequency is not always consistent as some simultaneously applied limits are more restrictive than others, e.g. limits on induced currents compared to those on external electric field or specific absorption rate (SAR). To evaluate the current induced in the human body in $1-90 \mathrm{MHz}$ range, we propose an equivalent circuit composed of two elements: the first one provides the voltage at human body mid-height and the second one describes the equivalent human body impedance. Then, assuming that the human body is equivalent to an antenna between 1 and $90 \mathrm{MHz}$, we calculate induced currents at the human body height. Using the relationship between external electric field and voltage at the body mid-height, we calculate the current along the body and suggest updated limits on induced currents more consistent with the external electric field limits.
\end{abstract}

Index Terms-Human body equivalent impedance circuit, induced currents, HF, VHF.

\section{INTRODUCTION}

Because of the increasing number of wireless systems, accurate dosimetric assessment of interactions between radiofrequency (RF) electromagnetic fields and human body is of importance. In the $1-90 \mathrm{MHz}$ range the limits established by ICNIRP [1] and IEEE [2] are defined in terms of external electric and magnetic fields, induced currents, current density and specific absorption rate (SAR). Tofani et al. reported that some limits are not fully consistent with each other, in particular in $90-104 \mathrm{MHz}$ range [3]. Although the limits on external electric field were not overpassed, the induced current exceeded the limits, which were the following: $45 \mathrm{~mA}$ for uncontrolled environment and $100 \mathrm{~mA}$ for controlled environment through one foot between $0.1 \mathrm{MHz}$ and $100 \mathrm{MHz}$ [4]. The same observation was made in a study by Gandhi et al. where the limits on currents induced by plane wave exposure up to $50 \mathrm{MHz}$ were not overpassed although limits on SAR $1 \mathrm{~g}$ were exceeded [5].

Several studies have used an equivalent antenna to model human body. Gandhi and Aslan have developed a humanequivalent antenna to measure the external current induced in a human body by RF exposure [6]. The antenna impedance was approximated by the human body impedance in $3 \mathrm{kHz}-110$ $\mathrm{MHz}$ range. Using this antenna allows induced current measurements without human subject. In 2003, Poljak et al. developed a human equivalent antenna model for transient electromagnetic exposure. They used thick cylindrical antennas to represent the human body and thin-wire approximation to evaluate the current induced in human body for a body exposed to a pulsed radiation between $50 \mathrm{~Hz}$ and $110 \mathrm{MHz}$ [7]. Recently Kibret et al. characterized the human body as a monopole antenna from $10 \mathrm{MHz}$ to $110 \mathrm{MHz}$ [8]. They gave physical dimensions of the equivalent cylindrical antenna and characterized it experimentally (in terms of radiation efficiency, reflection coefficient and impedance).

The main objective of this work is to analyze theoretically the relationship between induced currents and incident electric fields in the $1-90 \mathrm{MHz}$ frequency range. The actual limits of induced current for a controlled environment are used, i.e. 100 $\mathrm{mA}$ in one foot in $1-90 \mathrm{MHz}$ range [2]. The human body is modeled as a thick dipole antenna to calculate induced currents from the external applied electric field for plane wave exposure. The coupling between the thick dipole and the incident plane wave is modeled using an equivalent Thevenin circuit consisted of a voltage source $\mathrm{V}_{\text {th }}$ and impedance $\mathrm{Z}_{\text {th }}$ (section III). This circuit allows calculating currents induced in the dipole. We validate the equivalent circuit by comparing induced currents computed in a realistic human body model with those calculated using the Thevenin circuit. Finally we use this equivalent circuit to suggest in the last section more consistent limits on induced currents in respect to the limits on external electric field.

\section{MATERIALS AND METHODS}

\section{A. Anatomical human body model}

We used the anatomical voxel body model Duke from Virtual Family [9]. It is a $1.74 \mathrm{~m}$ high and $70 \mathrm{~kg}$ male model with a voxel size of $5 \mathrm{~mm}$. In total 77 tissues are modeled in simulations. We used a heterogeneous and homogenized model with the same body geometry. For the heterogeneous phantom, the dielectric properties were taken from Gabriel database [10]. For the homogeneous one, the equivalent tissue mass density was set at $1025 \mathrm{~kg} / \mathrm{m}^{3}$; its dispersive electromagnetic properties (i.e. relative permittivity and conductivity) are represented in Fig. 1. These are weighted average of the nine most present tissues from Hugo model of the Visible Human [11]. 

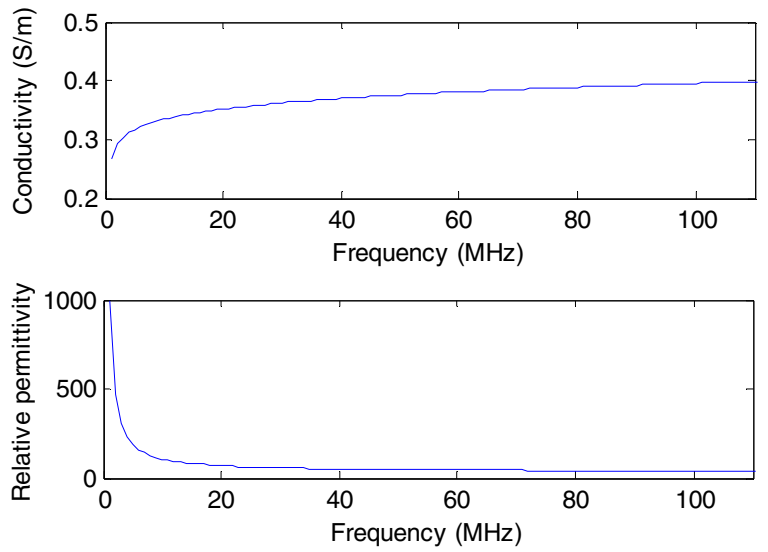

Fig. 1. Electromagnetic properties of the equivalent tissue used to homogenize Duke phantom

\section{B. Numerical modeling}

The phantom is exposed to a vertically polarized plane wave in the frequency range $1-90 \mathrm{MHz}$ with $\mathrm{E}$ rms field of $61 \mathrm{~V} / \mathrm{m}$. The numerical problems are solved using finite integration technique implemented in CST Microwave Studio. Matlab is used to calculate the induced current solving the Thevenin equivalent circuit.

\section{HUMAN-EQUIVALENT IMPEDANCE AND VOLTAGE CIRCUIT}

In this section, based on the standard Thevenin equivalent circuit (Fig. 2), we develop a circuit equivalent to human body for a vertically polarized plane wave exposure between 1 and $90 \mathrm{MHz}$ in free space. The circuit is composed of two elements. The first element is the Thevenin voltage $V_{t h}$ that evaluates the voltage source at mid-height of the phantom equivalent to the coupling with the external applied electric field $\left(E_{\text {ext }}\right)$. The second element is the Thevenin impedance $Z_{t h}$ that evaluates the human equivalent antenna impedance. We assume that human body is conductive enough (i.e. $\sigma>\omega \varepsilon_{0} \varepsilon_{\mathrm{r}}$ in the considered frequency range) to consider it as equivalent to a homogeneous thick dipole antenna to design our circuits. The load in Fig. 2 is set as a short circuit. Then with this circuit, we calculate induced current at mid-height of the phantom.

\section{A. Electric model of Thevenin voltage $V_{\text {th }}$}

The voltage at mid-height of the dipole antenna is the equivalent Thevenin voltage $V_{t h}$ and it depends on the antenna effective height. Therefore to design the voltage $V_{t h}$ in circuit, we have determined the effective height of Duke phantom depending on its physical parameters and frequency.

For frequencies below the Duke phantom resonance (i.e. $f$ $<65 \mathrm{MHz}$ ), the effective height of the antenna is $H / 2$ where $H$ is the height of the antenna equal to the physical height of the Duke phantom. At resonance, the effective height is assumed to be $\lambda / 2$ where $\lambda$ is the wavelength in vacuum.

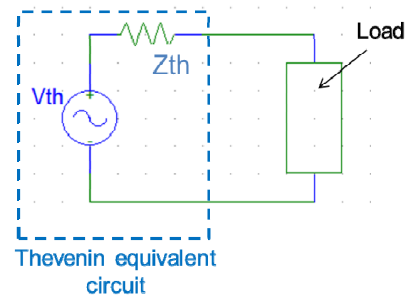

Fig. 2. Thevenin equivalent circuit modeling the voltage and impedance at mid-height of the phantom Duke

Between $65 \mathrm{MHz}$ and $200 \mathrm{MHz}$ we assume that the effective height decreases with a $-40 \mathrm{~dB} /$ decade slope. Therefore we can represent the voltage behavior in the thick dipole (i.e. in the phantom Duke) by a $2^{\text {nd }}$ order low-pass filter. $V_{\text {th }}$ is described by

$$
V_{t h}=\frac{E_{e x t}}{1+2 j m \omega / \omega_{0}+\left(\omega / \omega_{0}\right)^{2}}=\frac{E_{e x t}}{1+j R_{1} C_{1} \omega-L_{1} C_{1} \omega^{2}}
$$

where $E_{\text {ext }}$ is the rms external electric field, $\omega=2 \pi f$ the angular frequency, $\omega_{0}$ the angular frequency at resonance and $m$ the damping factor, $R_{l}, C_{l}$ and $L_{l}$ are the resistance, capacitor and inductance representing the lumped elements in the electric model of $V_{t h}$.

The voltage below and at resonance is defined by (2) and (3), respectively.

$$
\begin{aligned}
& V_{t h}=H / 2 E_{e x t} \\
& V_{t h}=\lambda / 2 E_{e x t}
\end{aligned}
$$

After simulating the Thevenin voltage of Duke from $1 \mathrm{MHz}$ to $300 \mathrm{MHz}$ (Fig. 4a), we set the damping factor $m=$ 0.35 and resistance $R_{l}=100 \Omega$. Because the resonance frequency appears for $H \sim \lambda / 2$, we can deduce $R$ and $C$ from equations (4) and (5). The electric model of $V_{t h}$ is described by Fig. 3a where $R_{l}=100 \Omega, L_{l}=265 \mathrm{nH}, C_{l}=13 \mathrm{pF}$ and the source generator $V_{2}$ is the external rms electric field $E_{\text {ext }}$ of the plane wave.

$$
\begin{gathered}
\omega_{0}=1 / \sqrt{L_{1} C_{1}} \\
m=R_{1} \sqrt{C_{1}} / 2 \sqrt{L_{1}}
\end{gathered}
$$

As the dipole is thick, we have introduced a corrective factor of 0.74 to take into account the antenna thickness (shortening factor [12]). Therefore the voltage at mid-height of the phantom is given by

$$
V_{t h}=\frac{0.74 E_{e x t}}{1+j R_{1} C_{1} \omega-L_{1} C_{1} \omega^{2}}
$$




\section{B. Electric model of human antenna impedance}

To design the electric model of the Thevenin impedance (equivalent to human body impedance), we simulated the Thevenin equivalent impedance $Z_{t h}$ of Duke from $1 \mathrm{MHz}$ to $300 \mathrm{MHz}$ (solid black curve in Fig. 4b). This simulation allows us designing an electric model of $Z_{t h}$ with the same impedance as Duke in the considered frequency range. At low frequencies (i.e. from $1 \mathrm{MHz}$ to $65 \mathrm{MHz}$ ), the body impedance behaves as a capacitor impedance because the imaginary part of $Z_{\text {th }}$ is negative. Close to resonance, it becomes a LC series circuit with $75 \Omega$ impedance at resonance. At higher frequencies (i.e. from $65 \mathrm{MHz}$ to $300 \mathrm{MHz}$ ), the thick dipole behaves as a radiation resistance which mean impedance of $200 \Omega$.

The electric model of the antenna impedance $Z_{t h}$ is shown in Fig.3b. $C_{h f}, R_{h f}$ and $L_{h f}$ are the components used for $f<f_{\text {resonance; }} C_{v h f}, R_{v h f}$ and $L_{v h f}$ are those used around the resonance while $R_{u h f}$ and $C_{u h f}$ are used for $f>f_{\text {resonance. }}$. These values are determined by the following equations, where $H$ is the height of Duke phantom, $r$ its mean radius and $c$ the speed of light in vacuum:

For $f<f_{\text {resonance }}$

$$
\begin{gathered}
C_{h f}=\frac{H}{120 c \ln (H / r)}=17.63 p F \\
R_{h f}=75 \Omega \\
L_{h f}=\frac{(2 H)^{2}}{C_{1}(2 \pi c)^{2}}=196 n H
\end{gathered}
$$

For $f \sim f_{\text {resonance }}$

$$
\begin{gathered}
C_{v h f}=C_{h f} \\
R_{v h f}=20 \Omega \\
L_{v h f}=\frac{(2 H)^{2}}{C_{v h f}(3 \pi c)^{2}}=86.9 n H
\end{gathered}
$$

For $f>f_{\text {resonance }}$

$$
\begin{aligned}
C_{u h f} & =\frac{C_{h f}}{4} \\
R_{u h f} & =200 \Omega
\end{aligned}
$$

To improve the agreement between the impedance values obtained with the heterogeneous Duke phantom in simulation and the impedance $Z_{\text {th }}$ obtained with the electric model in Fig. 3 b, we tuned values of some components as follows: $L_{h f}=$ $288 \mathrm{nH}, R_{v h f}=50 \Omega, L_{v h f}=25 \mathrm{nH}$ and $C_{u h f}=8.8 \mathrm{pF}$.

Fig. $4 \mathrm{a}$ represents the Thevenin equivalent voltage in the heterogeneous Duke phantom and the one calculated with the electric model of $V_{\text {th }}$ presented in Fig. 3a. Fig. 4b shows the Thevenin equivalent impedance in the heterogeneous Duke phantom and the Thevenin equivalent impedance calculated with the electric model given in Fig. 3b. The results calculated with the proposed Thevenin equivalent circuit are consistent with those calculated using Duke, validating the two electric models proposed for $V_{t h}$ and $Z_{t h}$. Then the induced current in (a)

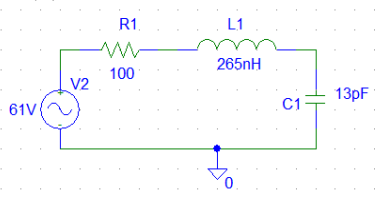

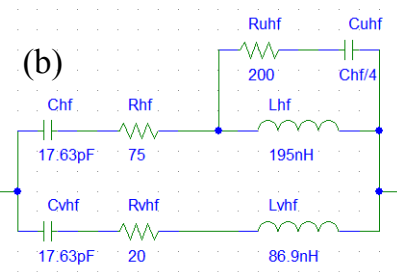

Fig. 3. Electric models of (a) voltage at mid-heigth of the dipole (Thevenin voltage $V_{t h}$ ) and (b) human equivalent impedance (Thevenin impedance $Z_{t h}$ )
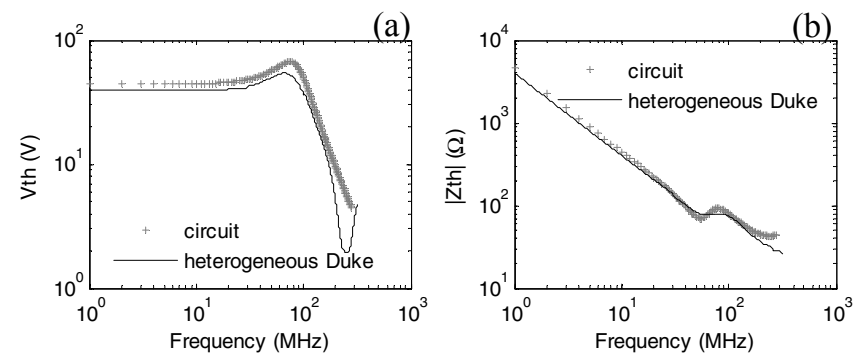

Fig. 4. Equivalent Thevenin (a) voltage and (b) impedance for the heterogeneous Duke phantom and equivalent Thevenin circuit

the thick dipole at mid-height is calculated as $V_{t h} / Z_{t h}$ ratio (Fig. 5).

In [13], the authors studied induced currents in human body for plane-wave exposure in $20-100 \mathrm{MHz}$ range in two cases: isolated from ground (same as in our study) and with feet in contact with the ground. In the isolated case, the induced current had a sinusoidal variation. King [14] developed analytical formulas to calculate electric current and electric field in the body using a cylindrical model. With this formulation, induced current calculated near the resonance had also a sinusoidal variation. Therefore we assume that the induced current along the human body in free space has a sinusoidal variation given by (15) where $I_{\max }$ is the induced current at mid-height of the body calculated by our circuits and $z$ the coordinate along the body.

$$
I(z)=I_{\max } \sin (\pi / 2 z+0.26)
$$

Because the body is not a perfect antenna, the current is not zero at the extremities, so we introduce a corrective coefficient 0.26 in (15). This coefficient is determined based on simulated induced current in Duke and induced currents calculated with the above described circuits.

\section{Validation of the circuits}

To validate the designed Thevenin circuit, we expose Duke phantom in free space to a vertically polarized plane-wave from 1 to $90 \mathrm{MHz}$ (E rms field is $61 \mathrm{~V} / \mathrm{m}$ ). Then we compare the computed induced current at mid-height (i.e. at $z=H / 2$ ) of the phantom to the currents calculated as $V_{t h} / Z_{t h}$ of the Thevenin equivalent circuit.

The mid-height induced current in the homogeneous and heterogeneous Duke have the similar behavior, being slightly higher in the heterogeneous phantom (maximum deviation is of $3 \mathrm{~dB}$ ) (Fig. 5). The current induced along the body in 
homogeneous Duke is nearly identical to the current induced in heterogeneous phantom (difference $<1 \mathrm{~dB}$, Fig. 6). This suggests that a homogeneous antenna can be used to represent induced current in human body.

The current induced at mid-height and calculated using the Thevenin equivalent circuit is close to those in Duke (maximum deviation of $1 \mathrm{~dB}$ ) (Fig. 5). Because the electric proposed models of $V_{t h}$ and $Z_{t h}$ give consistent values of induced current, voltage and impedance with Duke phantom, we consider that the Thevenin equivalent circuit is validated.

As the mid-height $(H / 2)$ induced current calculated by the Thevenin equivalent circuit is validated, we study in the following current distribution described by (15) and along the simulated Duke phantom. We compare induced currents along the body computed using heterogeneous and homogeneous Duke to those calculated by the Thevenin equivalent circuit and equation (15).

For the four frequencies represented in Fig. 6 (2 MHz, 30 $\mathrm{MHz}, 62 \mathrm{MHz}$ and $90 \mathrm{MHz}$ ), the distribution of induced current along the body is sinusoidal for heterogeneous Duke as well as for the equivalent circuit. The induced current

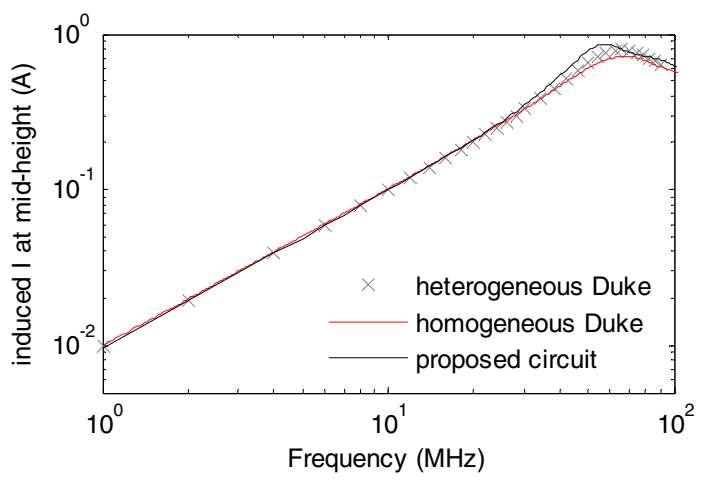

Fig. 5. Mid-length induced current in the heterogeneous, homogeneous Duke and in the equivalent dipole from 1 to $100 \mathrm{MHz}$
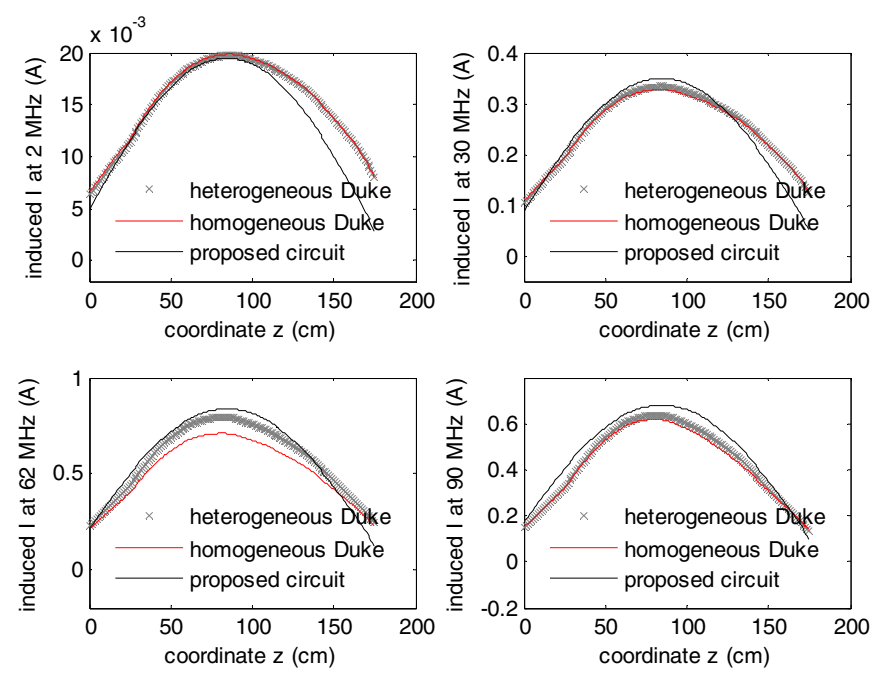

Fig. 6. Distribution of computed (for heterogeneous and homogeneous Duke) and determined using equation (15) induced current along human body at $2 \mathrm{MHz}, 30 \mathrm{MHz}, 62 \mathrm{MHz}$ and $90 \mathrm{MHz}$ calculated by (15) is in a good agreement with that computed in the heterogeneous phantom (maximum deviation is $1 \mathrm{~dB}$ ). The induced currents values at the feet $(z$ between 0 and $20 \mathrm{~cm}$ ) from the equivalent circuit and (15) are slightly lower than those of Duke (maximum deviation is $1.5 \mathrm{~dB}$ ). For the head ( $z$ between 160 and $180 \mathrm{~cm}$ ), the difference is higher (up to $8 \mathrm{~dB}$ at $2 \mathrm{MHz}$ ), but the limits on induced current given by ICNIRP [1] and IEEE [2] concern feet, so we consider our model still acceptable.

These results suggest that Thevenin equivalent circuit is an appropriate model for determining the induced current along the body for a plane wave exposure in $1-90 \mathrm{MHz}$ range, particularly from feet to torso. From the Thevenin equivalent circuit (via $V_{t h}$ ), we can describe induced current along the body as a function of the external electric field. In the next section, the equivalent circuit and equation (15) are used to propose new limits on induced current more consistent with external electric field limits reported in [2].

\section{LIMITS ON INDUCED CURRENT DEPENDING ON EXISTING EXTERNAL ELECTRIC FIELD LIMITS}

The limits on induced currents are defined for currents induced trough foot, so we consider that the induced current in foot can be measured at the ankle $(z=10 \mathrm{~cm})$. For a controlled environment the standard limit through a foot is $I_{\text {limit }}=100 \mathrm{~mA}$ $[2]$.

Using (15) and the proposed models, Fig. 7 demonstrates that to respect the actual limit on external electric field at 10 $\mathrm{MHz}$ (i.e.184 V/m), the induced current has to be lower than $80 \mathrm{~mA}$. Between 30 and $90 \mathrm{MHz}$, the limit on external electric field is $61 \mathrm{~V} / \mathrm{m}$ thus to respect those limits, the induced current in ankle has to be lower than $95 \mathrm{~mA}$ at $30 \mathrm{MHz}$ and lower than $180 \mathrm{~mA}$ at $50 \mathrm{MHz}, 70 \mathrm{MHz}$ and $90 \mathrm{MHz}$.

Therefore the actual limits on induced currents are more restrictive than external electric field for frequencies above $40 \mathrm{MHz}$. For frequencies below $40 \mathrm{MHz}$, the limits on external electric field are more restrictive. However we did not take into account the coupling with the magnetic field because the phantom is isolated thus only sensitive to electric field [15]. Therefore the same study with the magnetic field coupling could be done because for frequencies below $10 \mathrm{MHz}$, the ratio E/H from ICNIRP limits is low impedance (lower than $377 \Omega$ ) [1].

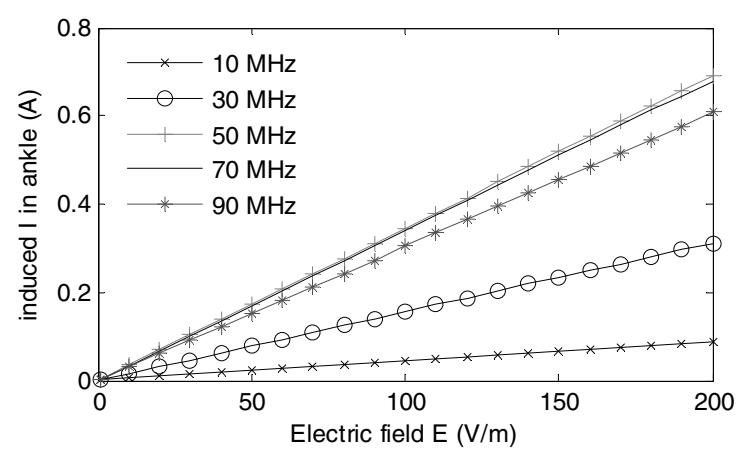

Fig. 7. Induced current in ankle as a fonction of external electric field at 10 $\mathrm{MHz}, 30 \mathrm{MHz}, 50 \mathrm{MHz}, 70 \mathrm{MHz}$ and $90 \mathrm{MHz}$ 


\section{CONCLUSION}

An equivalent Thevenin circuit has been proposed to evaluate human body impedance and voltage at mid-height for a vertically polarized plane wave exposure in $1-90 \mathrm{MHz}$ range. This circuit allows evaluating induced current along the human body depending on the external electric field for plane wave exposure. It provides an accurate estimate of the induced current compared to numerical results for a realistic human body model, particularly from feet to torso.

Finally, based on the proposed circuit and current distribution along the body, updated limits on induced current have been proposed depending on actual external electric field IEEE limits. This allows harmonizing induced current and external electric field limits, because currently induced currents limits are more restrictive than those of external electric field at frequencies above $40 \mathrm{MHz}$.

\section{ACKNOWLEDGMENT}

This work was supported by Thales Communications \& Security, French National Association of Research and Technology (ANRT) and French National Center for Scientific Research (CNRS).

\section{REFERENCES}

[1] ICNIRP, "Guidelines for limiting exposure to time-varying electric, magnetic and electromagnetic fields (up to $300 \mathrm{GHz}$ )", Health Phys., vol. 74 , pp. 494-522, 1998

[2] IEEE, "IEEE Standard for safety levels with respect to human exposure to radio frequency electromagnetic fields, $3 \mathrm{kHz}$ to $300 \mathrm{GHz}$ ", IEEE Std C95.1, 2005

[3] S. Tofani, G. d'Amore, G. Fiandino, A. Benedetto, O.P. Gandhi and J.Y. Chen, "Induced foot-currents in humans exposed to VHF radiofrequency EM fields", IEEE Trans. on Electromagnetic Compatibility, vol. 37, pp. 96-99, 1995
[4] IEEE, "IEEE Standard for safety levels with respect to human exposure to radio frequency electromagnetic fields, $3 \mathrm{kHz}$ to $300 \mathrm{GHz}$ ", IEEE Std C95.1, 1991

[5] O.P. Gandhi, J.Y. Chen and A. Riazi, "Currents induced in a human being for plane-wave exposure conditions $0-50 \mathrm{MHz}$ and for RF sealers", IEEE Trans. on Biomedical Engineering, vol. 33, no. 18, pp. 757-767, 1986

[6] O.P. Gandhi and E.E. Aslan, "Human equivalent antenna for electromagnetic fields", US Patent 5394164, Feb. 1995

[7] D. Poljak, C. Y. Tham, O.P. Gandhi and A. Sarolic, "Human equivalent antenna model for transient electromagnetic radiation exposure", IEEE Trans. on Electromagnetic Compatibility, vol. 45, pp. 141-145, 2003

[8] B. Kibret, A.K. Teshome and D.T.H. Lai, "Characterizing the human body as a monopole antenna", IEEE Trans. on Antennas and Propagation, vol. 63, pp. 4384-4392, 2015

[9] A. Christ, W. Kainz, E. Hahn, K. Honegger, M. Zefferer, E. Neufeld, W. Rascher, R. Janka, W. Bautz, J.Chen, B.Kiefer, P. Schmitt, H. Hollenbach, J. Shen, M. Oberle, D. Szczerba, A. Kam, J. Guag and N. Kuster, "The Virtual Family - Development of surface-based anatomical models of two adults and two children for dosimetric simulations", Phys. Med. Bio., vol. 55, pp. 23-38, 2010

[10] C. Gabriel, "Compilation of the dielectric properties of body tisses at RF and microwave frequencies", Final Technical Report of Occupational and Environmental Health Directoral, 1996

[11] "The Visible Human Project", available online at http://www.nlm.nih.gov/research/visible

[12] S.A. Schelkunoff, "Theory of antennas of arbitrary size and shape", Proceeding of the I.R.E., pp.493-521, 1941

[13] J.Y. Chen and O.P Gandhi, "RF Currents induced in an anatomicallybased midel of a human for plane-wave exposures $(20-100 \mathrm{MHz})$ ", Health Phys., vol. 57, pp. 89-98, 1989

[14] R. W. P. King, "Electric current and electric field induced in the human body when exposed to an incident electric field near the resonant frequency", IEEE Trans. on Microwave Theory and Tech., vol. 48, pp. 1537-1543, 2000

[15] J. Frere, M. Zhadobov, R. Sauleau, C. Lemoine, A. Alcaras and G. Le Cadre, "Influence de l'impédance d'onde sur les valeurs de débit d'absorption spécifique pour un fantôme de l'humain en bande HF", $18^{\text {ème }}$ colloque international et exposition sur la compatibilité électromagnétique, CEM 2016 Rennes, France, 2016 